\title{
Dramatic invasion of the orbit by periocular cutaneous squamous cell carcinoma
}

\author{
Aida Oulehri, Sara Elloudi, Hanane Baybay, Zakia Douhi, Fatima Zahra Mernissi
}

\author{
Department of Dermatology, University Hospital Hassan II, Fez, Morocco
}

Corresponding author: Aida Oulehri, MD, E-mail: aidaoulehri@gmail.com

\begin{abstract}
The periocular skin is susceptible to numerous benign and malignant neoplasms. Malignant skin tumors of the periocular area are very particular; they can present differently, are rapidly aggressive and pose a real therapeutic challenge. Aggressive forms occur mostly in immunocompromised individuals. A complete destruction of the orbit is rare and the initial seat is most often the eyelid. We report the case of an immunocompetent 70-year-old patient with destruction of the entire orbital region including the eyeball secondary to the extension of squamous cell carcinoma of the internal canthus.
\end{abstract}

Key words: Periocular squamous cell carcinoma; Internal canthus; Orbit destruction; Immunocompetent

\section{INTRODUCTION}

The periocular area, composed of the upper and lower eyelids and the internal and external canthus, is the frequent site of several benign and malignant skin tumors. Between $5 \%$ and $10 \%$ of cutaneous malignancies occur periorbitally, with basal cell carcinoma (BCC) reported as the most common malignant periocular tumor, followed by squamous cell carcinoma (SCC), sebaceous gland carcinoma (SGC), and cutaneous melanoma (CM) [1]. Our 70-year-old patient had a spectacular destruction of the left orbital region secondary to an initial cutaneous squamous cell carcinoma.

\section{CASE REPORT}

A 70-year-old patient with no significant pathological history, other than chronic sun exposure. Presented one year ago a papule of the medial canthus of the left eye, which rapidly increased in size, neglected by the patient until invasion of the adjacent eye. The patient consulted at this stage, with a skin biopsy returned in favor of a well-differentiated keratinizing squamous cell carcinoma without vascular emboli or peri-nervous invasion.
Clinical examination revealed the presence of an ulcerous budding tumor of the left orbital region, reaching up to the eyebrow at the top, the wing of the nose inwards and pushing the left eye outwards, measuring six $\mathrm{cm}$ long with an infiltrated and fixed base, the background was burgeoning and the surface purulent (Fig. 1). The dermoscopic appearance was that of a malignant keratinizing tumor with a red background, shiny white oval and round areas with anarchic arrangement and irregular linear vascular structures (Fig. 2). All the ganglion areas were free. An ultrasound of the lymph node drainage areas came back normal, a craniofacial CT scan showed a left para- septal orbital tissue process infiltrating the frontal, temporal, nasal and homolateral jugular skin soft tissues, measuring $60 \times 67 \times 73 \mathrm{~mm}$ in diameter, it infiltrates backwards the intra-orbital fat and oculomotor muscles, it lyses the nasal bones and stenoses the nasolacrimal duct. There is no intracranial extension. The patient underwent orbital exenteration with secondary reconstruction, final microscopic margins were negative, current follow-up is eight months with well evolved (Fig. 3).

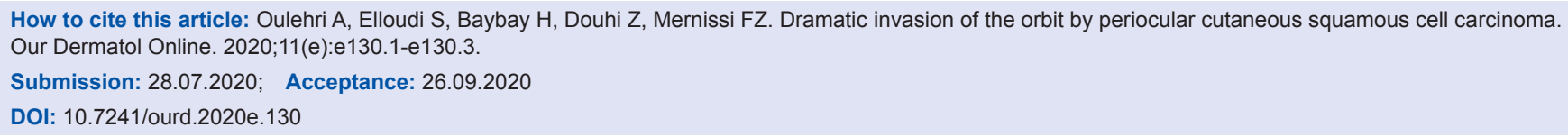




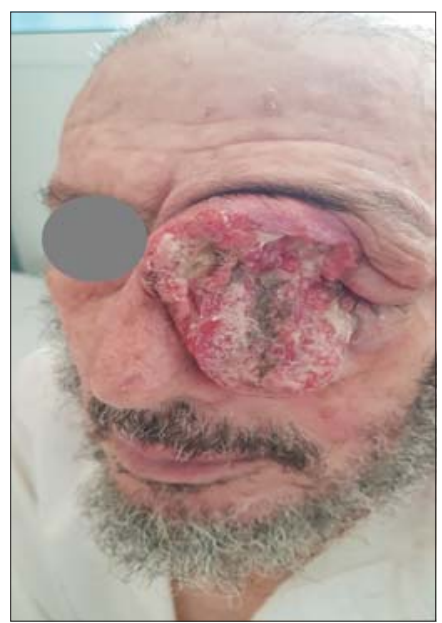

Figure 1: Ulcerous budding tumor of the left orbital region, presses the left eye outwards.

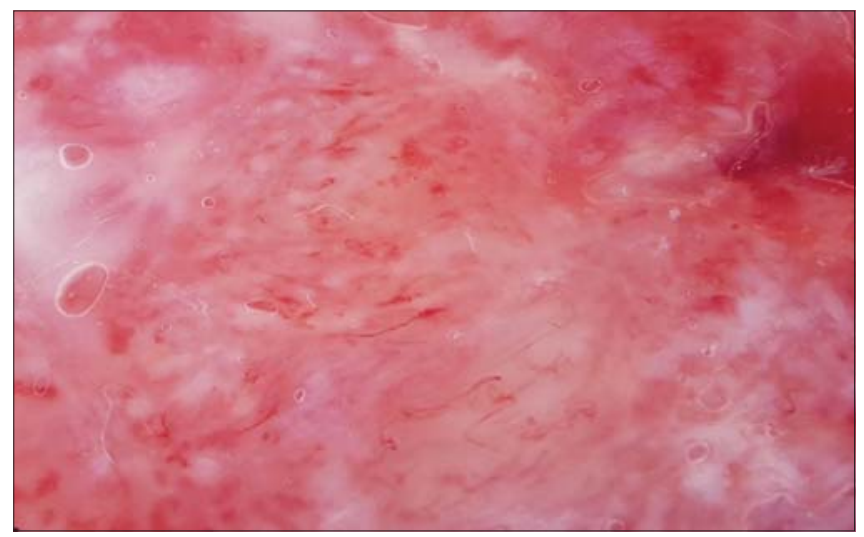

Figure 2: Dermoscopic appearance make of a red background, shiny white oval and round areas and anarchic irregular linear vascular structures.

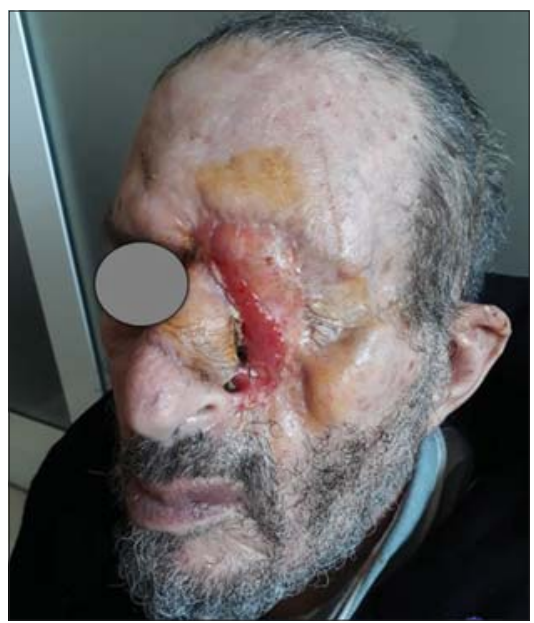

Figure 3: Clinical control of the patient after eight months of the surgical procedure.

\section{DISCUSSION}

The majority of periocular SCC occur on the lower eyelid, followed by the medial canthus, upper eyelid, and lateral canthus [2]. Immunosuppression is a well-known risk factor for SCC, and periorbital SCC has been reported in renal transplant recipients and individuals with the human immunodeficiency virus (HIV) [3-5]. Our patient had no immunosuppressive field and his HIV serology was negative. There are multiple reports of orbitally invasive SCC, most often in neglected, aggressive tumors [6-8], these cases are all published in ophthalmology journals and the initial tumor is most often palpebral. The initial site at medial canthus is much less frequent [9].

SCC behaves more aggressively than BCC, and lymph node metastasis and perineural invasion (PNI) occur more frequently in SCC [10]. SCC can be locally invasive and destructive and can metastasize through lymphatic, perineural, or hematogenous routes, with high morbidity and mortality. The lymphatic system is the most common site of periocular SCC metastasis, and studies have reported the incidence of regional lymph node invasion to be between $1 \%$ and 24.3\% [2]. Early detection and management of lymph node involvement is essential because regional lymphatic spread from a primary tumor has unfavorable prognostic implications. Palpation of lymph nodes should be part of the clinical examinations of patients with periocular SCC.

Orbital exenteration refers to complete excision of periorbital tissues, orbital contents, and orbital fat, extraocular muscles, bulbar conjunctiva, and sclera. It is indicated for tumors of the orbit, periorbita, conjunctiva, globe, and paranasal sinuses that have invaded the orbital apex, retrobulbar fat, extraocular muscles, bulbar conjunctiva, or sclera and which are potentially fatal, progressive, and cannot be effectively treated by other modalities [11]. Therefore, negative surgical margins are considered an important part of the surgical goal when considering exenteration; the authors found worse prognosis with positive final surgical margins. For patients with periorbital non-melanoma skin cancer with orbital invasion, orbital exenteration offers an overall 2-year survival of $\sim 80 \%$ [12].

\section{CONCLUSION}

We conclude from this case report that skin tumours of the periocular region are frequently aggressive and often require the use of mutilating surgical treatment. It is therefore essential to treat any tumor of this anatomical region rapidly and not hesitate to perform a skin biopsy if there is any doubt of malignancy. 


\section{REFERENCES}

1. Cook BE, Bartley GB. Treatment options and future prospects for the management of eyelid malignancies: an evidence-based update. Ophthalmology. 2001;108:2088-8; quiz 2099-2100, 2121.

2. Slutsky JB, Jones EC. Periocular cutaneous malignancies: a review of the literature. Dermatol Surg. 2012;38:552-69.

3. McNamara KJ, Fernandez C, Saunders TFC, Ahsan F. Human immunodeficiency disease in new diagnoses of head and neck squamous cell cancer: are we testing? J Laryngol Otol. 2019;133:1038-40.

4. Albanese G, Abercrombie LC. The importance of immunosuppression as risk and prognostic factor for periorbital non-melanoma skin cancers. Eye (Lond). 2018;32:159-60.

5. Manyam BV, Garsa AA, Chin RI, Reddy CA, Gastman B, Thorstad W, et al. A multi-institutional comparison of outcomes of immunosuppressed and immunocompetent patients treated with surgery and radiation therapy for cutaneous squamous cell carcinoma of the head and neck. Cancer. 2017;123:2054-60.

6. Soysal HG, Markoç F. Invasive squamous cell carcinoma of the eyelids and periorbital region. Br J Ophthalmol. 2007;91:325-9.

7. Wawrzynski J, Tudge I, Fitzgerald E, Collin R, Desai P, Emeriewen $\mathrm{K}$, et al. Report on the incidence of squamous cell carcinomas affecting the eyelids in England over a 15-year period (2000-2014). Br J Ophthalmol. 2018;102):1358-61.
8. Quigley C, Deady S, Hughes E, McElnea E, Zgaga L, Chetty S National incidence of eyelid cancer in Ireland (2005-2015). Eye (Lond). 2019;33:1534-9.

9. Mercer M, Leyngold I, Margo CE. Squamous cell carcinoma of medial canthal skin with perineural invasion of orbit. Ophthalmic Plast Reconstr Surg. 2016;32:e50.

10. Verburg M, Lang M, Mühlstädt M, Klein A, Schauber J, Sattler EC, et al. Cutaneous squamous cell carcinoma with perineural invasion: report on eight cases and review of the literature. Dermatology (Basel). 2015;230:135-42.

11. Hoffman GR, Jefferson ND, Reid CBA, Eisenberg RL. Orbital exenteration to manage infiltrative sinonasal, orbital adnexal, and cutaneous malignancies provides acceptable survival outcomes: an institutional review, literature review, and meta-analysis. J Oral Maxillofac Surg. 2016;74:631-43.

12. Gerring RC, Ott CT, Curry JM, Sargi ZB, Wester ST. Orbital exenteration for advanced periorbital non-melanoma skin cancer: prognostic factors and survival. Eye (Lond). 2017;31:379-88.

Copyright by Aida Oulehri, et al. This is an open-access article distributed under the terms of the Creative Commons Attribution License, which permits unrestricted use, distribution, and reproduction in any medium, provided the original author and source are credited.

Source of Support: Nil, Conflict of Interest: None declared. 